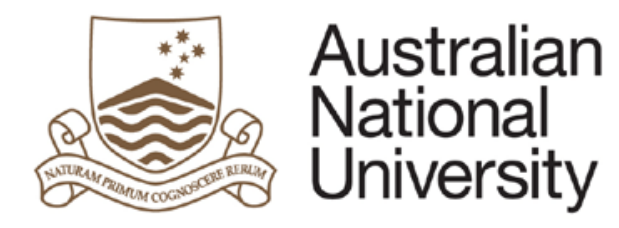

Centre for Applied Macroeconomic Analysis

The Australian National University

CAMA Working Paper Series

May, 2012

TESTING EXTERNAL HABITS IN AN ASSET PRICING MODEL

\title{
M.Boschi
}

University of Rome 3

Centre for Applied Macroeconomic Analysis (CAMA), ANU

S. d'Addona

University of Rome 3

Centre for Applied Macroeconomic Analysis (CAMA), ANU

\section{A. Goenka}

National University of Singapore

Centre for Applied Macroeconomic Analysis (CAMA), ANU

CAMA Working Paper 20/2012 http://cama.anu.edu.au 


\title{
Testing external habits in an asset pricing model
}

\author{
M.Boschia ${ }^{\mathrm{a}, \mathrm{c}}$, S. d'Addona ${ }^{\mathrm{b}, \mathrm{c}}$, A. Goenka ${ }^{\mathrm{d}, \mathrm{c}, *}$ \\ ${ }^{a}$ Department of Public Institutions, Economy and Society, University of Rome 3, Via G. Chiabrera, 199, \\ I-00145 Rome; +39-06-5733-5410. \\ ${ }^{b}$ Department of International Studies, University of Rome 3, Via G. Chiabrera, 199, I-00145 Rome; \\ +39-06-5733-5331. \\ ${ }^{c}$ Centre for Applied Macroeconomic Analysis, Research School of Economics, Australian National \\ University, Australia. \\ ${ }^{d}$ Department of Economics, National University of Singapore, AS2 Level 6, 1 Arts Link, 117570 \\ Singapore; +6565163961.
}

\begin{abstract}
The asset pricing model with external habit formation predicts that the equity premium depends on consumption changes relative to the habit level, implying a response that varies over the business cycle. We test this implication using a VAR model of the U.S. postwar economy whose time-varying parameters are estimated conditioning on Markov-switching regimes that shift according to the business cycle phases. This enables us to test whether the non-linear response predicted in the model is significant. The results show that the response of the equity premium to consumption shocks is insignificantly different over the business cycle. We interpret this as evidence against the external habit formation hypothesis. Keywords: Habit formation, Equity premium, Business cycles, Markov-switching models, Time-varying VAR, Regime-dependent impulse response functions.

JEL Classification: E21, E32, E44, G11, G12.
\end{abstract}

\section{Introduction}

In the past two decades there has been growing interest in the implications of preferences that are not time separable, with a focus on those exhibiting habit formation. When consumers have preferences with habit formation, current utility depends not only on current

\footnotetext{
*Corresponding author

Email addresses: mboschi@uniroma3.it (M.Boschi), daddona@uniroma3.it (S. d'Addona), goenka@nus.edu.sg (A. Goenka) 
expenditure, but also on a "habit stock" formed by past expenditures. For a given level of current expenditure, a larger habit stock lowers utility. This implies that habit formation causes consumers to adjust slowly to shocks to permanent income and it can explain the "excess" smoothness of aggregate consumption documented by [8] as well as by [10]. ${ }^{1}$ In addition, habits have provided a partial solution to the equity premium puzzle, since they increase the disutility associated with large declines in consumption (see, e.g., [1], [12], and [7]). Habit formation has also been pushed forward as a solution to a number of other empirical anomalies associated with permanent income hypothesis models of inter-temporal consumption behavior. [9] use habits to explain the direction of causality from national growth rates to aggregate saving. [22] shows that habits allow the delayed response of consumption and inflation to monetary shocks that is observed empirically. [23] proposes a solution to the "excess volatility" problem of inter-temporal current account models by incorporating consumption habits in the standard model.

In this paper we test the hypothesis of habit formation by assessing the empirical implications of a simple model of portfolio decision in which the investor's behavior is affected by (a slow moving) external habit based on past aggregate consumption, as in [1] and [7]. One of the key insights of habit models is that as investors' consumption falls to the habit level, the curvature of the utility function increases making investors act as if they were more risk averse. This increases the risk premium required to hold risky assets. Such effect will differ depending on the relative position of consumption with respect to habits: As the economy is expanding, consumption is large relative to the habit level and a consumption shock will have a smaller effect than during business cycle contractions, when consumption is closer to habits. This reflects the lower risk aversion that investors exhibit in booms with respect to recessions. Therefore, the changing risk aversion across the business cycle phases is the means through which a consumption shock of a given magnitude exerts different effects on the equity premium. We test this implication of external habits formation using the following approach. We estimate a VAR model of the risk-free rate of return, the realized excess

\footnotetext{
${ }^{1}$ Such a property of habit formation has been exploited to impose consumption persistence in the construction of DSGE models for policy analysis (e.g. [35]).
} 
return on equity and consumption of nondurable goods. The first two variables are treated as endogenous, while the latter is treated as exogenous following the argument detailed in section 3. The VAR coefficients are time-varying according to the unknown, underlying state of the economy, which is allowed to switch between boom and recession. Although agents cannot observe this state, we assume they can infer the probabilities of being in each of the two states by looking at the past and present rate of consumption growth, which is assumed to follow a two-state Markov-switching exogenous process. These probabilities are used to estimate the time-varying parameters of the VAR model. The impulse response function of the excess return measures the change in expectations about future excess returns, i.e. the equity premium, following a consumption shock. Under the external habits formation hypothesis, the impulse response function is expected to be significantly different across the business cycle states of the economy, captured by the two regimes in which the model can be. We emphasize that this approach innovates with respect to the large literature on Markov-switching VAR models where the regime shifts are induced by the variables dynamics and inter-relationship in such a complicated way that hinders the interpretation of regimes. By contrast, here the regime shifts are governed by only one of the variables included in the VAR (consumption) hence making the interpretation of the economy states straightforward. ${ }^{2}$ Moreover, in the Markov-switching VAR literature (see, e.g., [16]), the estimation of regimes and coefficients are carried out using the EM algorithm popularized by [25], while here the regime probabilities are estimated in advance using the MCMC algorithm, and then fed in the VAR model to obtain the autoregressive parameters. Notice that this testable implication is specific to models with external habit formation with utility depending on the difference between the consumption level and habits stock. In fact, the [1] specification of the utility function implies constant risk aversion, while with the standard CRRA utility the effect of consumption shocks on the equity premium is independent of the

\footnotetext{
${ }^{2}$ See the previous version of this paper, [3], for a modeling strategy where the probabilities of regime shifts and, consequently, the VAR parameters, are estimated conditioning on the process of all the endogenous variables of the model. In this case it is unclear what the regimes refer to. Notice that that model also differs from the present one in treating consumption as endogenous, while here consumption enters the VAR model as an exogenous variable.
} 
business cycle phase. Finally, assuming a general non-linear relationship between consumption and the equity premium such as decreasing risk aversion (see [4]) does not imply that the premium depends on the business cycle as what is important is the level of consumption and not its deviation from the habit stock as in the habit formation specification. The latter has a natural business cycle interpretation. In this sense, the empirical methodology applied below is a valid test of a specific form of time-varying risk aversion, i.e. that deriving from the external habit formation hypothesis in financial markets.

Our study relates to a large body of literature on habits testing. Notwithstanding the wide use of habit formation as a device to solve empirical puzzles, tests of this hypothesis based on aggregate consumption data yield only mixed conclusions. [13], [17], and [26] find very little evidence of habit formation in U.S. aggregate monthly consumption data, and [32] produces similar results with U.S. quarterly consumption data. In contrast, [21] find large and statistically significant amounts of habit formation in monthly, quarterly, and annual U.S. consumption data, while [5] find some habit formation in aggregate Japanese consumption. These widely varying conclusions stem from differences in the estimated firstorder conditions, data, and instruments. Moreover, all studies of habit formation based on aggregate data face a common problem: their conclusions hinge on the serial correlation of aggregate consumption growth, which is appreciably influenced by a number of factors unrelated to preferences, such as time averaging, aggregation across individuals, and data construction methods. To overcome this issue, [14] uses data on food expenditures from the Panel Study on Income Dynamics(PSID) to estimate the first-order condition of a life-cycle consumption model with habit formation. She argues that such data are far less influenced by factors distorting the serial correlation of aggregate consumption. Her results yield no evidence of habit formation at the annual frequency. ${ }^{3}$ Nevertheless, since habit formation and durability parameters cannot be estimated separately with PSID data, Dynan's result could be heavily influenced by durability in consumption figures that partially, or even totally, obscure habit formation.

\footnotetext{
${ }^{3}$ Note that this is not a test at the business cycle frequency.
} 
Besides problems related to data aggregation and measurement errors, as discussed by [14], all tests reviewed above rely crucially on heavy assumptions about the Euler equations. In addition, a series of issues arise when estimating consumption Euler equations with households data, and the solutions provided by the existing literature are designed for linear equations, while the first-order condition of a consumption model with habits is highly nonlinear.

Our paper draws on a completely different approach which is immunized of such problems by focusing on aggregate effects of consumption shocks, due, for example, to productivity or preference changes, on financial markets behavior. We do so by using a novel approach to estimating VAR models whose time-varying coefficients are subject to regime switching.

We test the null that the response of the equity premium to a consumption shock does not vary over the states of the economy, i.e. the business cycle, on the U.S. postwar economy. The estimation results show that, as expected, the equity premium reacts positively to a negative shock to consumption. However, the response seems to be insignificantly different from zero and, most importantly, across different states of the economy according to the small sample properties of bootstrapped confidence intervals. This empirical evidence is incompatible with the habit models prediction that, as investors' consumption fall to the habit level, investors become more risk averse and the required equity premium will show sharper reactions to a consumption shock. Thus, we cannot reject the null and interpret the evidence as against the hypothesis of habit formation in the U.S. at a macroeconomic level.

The remainder of the paper is structured as follows: Section 2 outlines the implications of an exchange economy model with external habit formation. Section 3 discusses the testing strategy and empirical methodology while section 4 presents the data used in the estimation, the regimes estimation and some preliminary analysis. Finally, section 5 discusses the results and section 6 concludes.

\section{The model}

We model utility as a function of the difference between aggregate consumption and the habit level, the latter depending on per capita aggregate consumption, i.e. external habit. 
Unlike models in which utility is a function of the ratio of consumption to the habit stock $([1,2])$ and, hence, the relative risk aversion is constant, difference models generate time variation in the equilibrium equity premium because relative risk aversion varies countercyclically. This implication is crucial for our habits testing strategy.

The representative investor maximizes the following utility function:

$$
U_{0}=E_{0} \sum_{t=0}^{\infty} \beta^{t} u\left(C_{t}-X_{t}\right)
$$

where $E_{t}$ is the expectation operator conditional on information available at date $t, \beta \in(0,1)$ is the constant subjective time-preference factor, $u(\cdot)$ is the twice-continuously differentiable, strictly increasing, and strictly concave period utility function, i.e. $u^{\prime}(\cdot)>0, u^{\prime \prime}(\cdot)<0, C_{t}$ is real consumption on period $t, X_{t}$ is the external habit level. The price of the consumption good is normalized to 1 . Notice that in the literature on habits, $X_{t}$ is assumed to adjust slowly to consumption.

There are only two assets, a risk-free bond and a risky equity.

The period-by-period budget constraint is given by:

$$
B_{t+1}^{f}+x_{t+1} P_{t}=\left(1+r_{t}^{f}\right) B_{t}^{f}+x_{t}\left(D_{t}+P_{t}\right)-C_{t}
$$

where $B_{t}^{f}$ is the net real risk-free bond purchase at time $t-1, x_{t}$ is the fractional share of the risky equity purchased by the agent in period $t-1, P_{t}$ denotes the date $t$ real market price of equity, $r_{t}^{f}$ is the net real interest rate on the risk-free bond $B_{t}^{f}$ between date $t-1$ and $t, D_{t}$ is the dividend paid on equity at time $t$. Equation (2) expresses the link between period $t$ saving and period $t+1$ financial wealth.

Maximizing the utility function (1) subject to the constraint (2) with respect to $B_{t+1}^{f}$ and $x_{t+1}$ gives the following Euler equations:

$$
u^{\prime}\left(C_{t}-X_{t}\right) P_{t}=\beta E_{t}\left[u^{\prime}\left(C_{t+1}-X_{t+1}\right)\left(D_{t+1}+P_{t+1}\right)\right]
$$

and 


$$
u^{\prime}\left(C_{t}-X_{t}\right)=\left(1+r_{t+1}^{f}\right) \beta E_{t}\left[u^{\prime}\left(C_{t+1}-X_{t+1}\right)\right] .
$$

Define the ex post net real rate of return on the risky equity as:

$$
r_{t+1} \equiv \frac{D_{t+1}}{P_{t}}+\frac{P_{t+1}-P_{t}}{P_{t}}
$$

from (3), recalling that $E(X Y)=\operatorname{Cov}(X, Y)+E(X) E(Y)$, we obtain:

$$
\begin{aligned}
u^{\prime}\left(C_{t}-X_{t}\right)= & \beta \operatorname{Cov}_{t}\left[u^{\prime}\left(C_{t+1}-X_{t+1}\right),\left(1+r_{t+1}\right)\right] \\
& +\beta E_{t}\left[u^{\prime}\left(C_{t+1}-X_{t+1}\right)\right] E_{t}\left(1+r_{t+1}\right) .
\end{aligned}
$$

Dividing both sides by $u^{\prime}\left(C_{t}-X_{t}\right)$, using (4) to substitute out $\beta E_{t} u^{\prime}\left(C_{t+1}-X_{t+1}\right) / u^{\prime}\left(C_{t}-\right.$ $X_{t}$ ), and rearranging, we obtain:

$$
E_{t}\left(1+r_{t+1}\right)-\left(1+r_{t+1}^{f}\right)=-\left(1+r_{t+1}^{f}\right) \operatorname{Cov}_{t}\left[\beta \frac{u^{\prime}\left(C_{t+1}-X_{t+1}\right)}{u^{\prime}\left(C_{t}-X_{t}\right)}, r_{t+1}\right]
$$

Equation (6) is the crucial expression of the consumption-based CAPM: it links the equity premium to the covariance between the asset return and the stochastic discount factor (SDF) defined as $\beta u^{\prime}\left(C_{t+1}-X_{t+1}\right) / u^{\prime}\left(C_{t}-X_{t}\right)$.

If we specify the utility function as in [7]:

$$
U_{0}=E_{0} \sum_{t=0}^{\infty} \beta^{t} \frac{\left(C_{t}-X_{t}\right)^{1-\gamma}-1}{1-\gamma}
$$

where $\gamma$ is a risk aversion parameter, then, the following proposition holds.

Proposition 2.1. The equity premium is negatively related to the surplus consumption level:

$$
E_{t}\left(r_{t+1}\right)-r_{t+1}^{f} \simeq\left(1+r_{t+1}^{f}\right) \beta \frac{\gamma}{C_{t}-X_{t}} \operatorname{Cov}_{t}\left[\left(C_{t+1}-X_{t+1}\right), r_{t+1}\right]
$$


where

$$
\frac{\gamma}{\left(C_{t}-X_{t}\right) / C_{t}}=\frac{-C_{t} u^{\prime \prime}\left(C_{t}-X_{t}\right)}{u^{\prime}\left(C_{t}-X_{t}\right)}
$$

denotes the local curvature of the utility function with external habits and $C_{t}-X_{t}$ is the surplus consumption level with respect to habits, i.e. how far consumption is from the habits level.

Proof. See Appendix A.

Proposition 2.1 is the key to interpret the role of risk aversion in the model: With external habit formation the equity premium depends on the covariance between the risky asset's return and the surplus consumption level. If the covariance term is, say, positive, the asset does not provide a hedge against consumption fluctuations and the investor will require an excess return with respect to the risk-free bond's return to be persuaded to hold the risky asset. Furthermore, and most importantly for our analysis, a decrease (increase) in the consumption level, given habits, will decrease (increase) the surplus consumption level which, in turn, will increase (decrease) the expected excess return, i.e. the equity premium. This is because the local curvature of the utility function, which measures relative risk aversion, depends on both the risk aversion parameter, $\gamma$, and on how far consumption is from the habit level, i.e. the surplus consumption level, $C_{t}-X_{t}$. Hence, risk aversion is time-varying: Changes in the consumption level, given habits, will affect the equity premium through a change in the coefficient of relative risk aversion, i.e. a change in the local curvature of the utility function. If there is no habit formation or $X_{t}$ is always zero, then the model reduces to the CRRA specification.

\subsection{Model predictions}

In this subsection we analyze some crucial theoretical predictions of the model outlined above. From Proposition 2.1 the following corollary derives.

Corollary 2.2. The effect of consumption changes on the equity premium is nonlinear since its magnitude is inversely related to the surplus consumption level. 
Proof. See Appendix A.

Proposition 2.1 and Corollary 2.2 state that consumption changes have a large effect on the equity premium when the consumption level, $C_{t}$, is close to the habits stock, $X_{t}$, i.e. when the surplus consumption level is small, while consumption changes have a small effect on the equity premium when the surplus consumption level is large. Again, this nonlinear relationship between consumption and the equity premium works through the changing risk aversion: As consumption is close to habits, investors will be more risk averse and will exhibit sharper reactions to consumption changes in terms of higher equity premia.

It is worth emphasizing that Corollary 2.2 is specific to the external habits utility specification when compared to other classes of preferences now popular in the asset pricing literature. It is well known that the power utility specification, belonging to the CRRA family, has a constant local curvature and thus implies a constant coefficient of risk aversion. This is also the case for the $[19,20]$ recursive utility. In fact, as shown by [37], in this case the local curvature is constant and equal to $\gamma$. As discussed earlier a general specification of time-varying equity premia (e.g. one deriving from decreasing risk aversion as in 4) is ruled out since the nonlinear relationship between consumption changes and the equity premium does not necessarily depends on business cycle phases. Hence, the empirical testing strategy developed below is indeed a test of the external habit formation hypothesis.

\section{Testing strategy}

As discussed in the previous section, an implication of the external habit formation models, such as the one of [7], is that a decrease in consumption towards habits increases the relative risk aversion coefficient. This increase in risk aversion, in turn, leads to a lower demand for risky assets and an increase in the expected equity premium. However, as we have seen, the effect of a change in consumption on the equity premium has a different magnitude depending on the relative position of consumption with respect to habits, i.e. depending on the surplus consumption level: it will be large (small) when the surplus consumption is small (large). Notice that a direct test of this nonlinear relationship is unfeasible since 
the habits stock is unobservable. Nevertheless, we can bypass this difficulty building on the standard hypothesis that the habits stock is slow moving, so that it becomes straightforward to associate the surplus consumption level changes to the business cycle phases: When the economy is in a boom state consumption will increase and, given the slow moving habits stock, the surplus consumption level will become large. On the other hand, during economic recessions consumption will decrease towards habits reducing the surplus consumption level. Such a relationship between cyclical variations of consumption and habits is a standard feature of the habits literature (see [7]).

We assume that agents cannot observe the underlying state of the economy, i.e. the business cycle phase, but can infer it from external signals. In our specification we use the consumption growth rate as signal of the state of the economy, and we model it as a state dependent process in its mean with i.i.d. normal innovations:

$$
\Delta c_{t}=\mu\left(s_{t}\right)+\epsilon_{t}
$$

where $c_{t}$ is the logarithm of the consumption level, $C_{t}, \mu$ is the mean of the process and $\epsilon_{t}$ is a random, Gaussian, shock. Notice that this closes the model of section 2 as a general equilibrium exchange economy whose representative agent receives the endowment stream given by the consumption process (8).

The state of the economy, $s_{t}$, follows a hidden Markov chain with transition probabilities matrix $\mathbf{P}$ (see [24]). Agents infer the underlying state of the economy by formulating the posterior probability of being in each state based on data available through date $t$ and basing on the knowledge of the population parameters. Supposing the economy can switch among $m$ states, the $j$-th element of the $m \times 1$ vector $\widehat{\xi}_{t \mid t}$ of filtered posterior probabilities is given by:

$$
\widehat{\xi}_{j, t \mid t}=\operatorname{Pr}\left\{s_{t}=s \mid \Omega_{t}\right\}
$$

where $\Omega_{t}$ denotes the information set including all data and parameters up to time $t$. In our model, $s=b, r$ where $b$ denotes the "boom" state of the economy, and $r$ the "recession" 
state. Agents update their posterior probability according to:

$$
\widehat{\xi}_{t \mid t}=\frac{\left(\widehat{\xi}_{t \mid t-1} \odot \zeta_{t}\right)}{\mathbf{1}^{\prime}\left(\widehat{\xi}_{t \mid t-1} \odot \zeta_{t}\right)}
$$

where $\odot$ denotes element-by-element multiplication, 1 denotes an $(m \times 1)$ vector of ones, $\mathbf{P}$ is the $(m \times m)$ matrix of transition probabilities and $\zeta_{t}$ is a vector of Gaussian density functions of consumption growth rates conditional on the state $s_{t}$ :

$$
\zeta_{t}=\left[\begin{array}{c}
f\left(\Delta c_{t} \mid s_{t}=1, \Omega_{t-1}\right) \\
\vdots \\
f\left(\Delta c_{t} \mid s_{t}=m, \Omega_{t-1}\right)
\end{array}\right]
$$

with the density of $\Delta c_{t}$ conditional on state $s_{t}$ defined as:

$$
f\left(\Delta c_{t} \mid s_{t}=1, \Omega_{t-1}\right)=\frac{1}{\sqrt{2 \pi \sigma}} \exp \left\{-\frac{\left(\Delta c_{t}-\mu\left(s_{t}\right)\right)^{2}}{2 \sigma^{2}}\right\}
$$

To derive the empirical specification of our theoretical model, we follow the approach proposed by [6] in modeling the risk-free rate, the equity premium and consumption as elements of a vector autoregression (VAR). From equation (8) we know that the endowment log-level is driven by an exogenous random walk process, whose growth rate is state dependent in its mean and is subject to i.i.d. normal innovations. Therefore, the consumption log-level must enter the VAR model as an exogenous variable. In choosing this specification we are comforted by the fact that over the sample period considered only a small fraction of U.S. consumers hold stocks, which makes unlikely that aggregate consumption is endogenously determined by the equity premium (see [31]). ${ }^{4}$ Therefore, we define a vector $\mathbf{y}_{t}$ of endogenous variables whose $K_{y}$ elements are the risk-free real interest rate and the excess return, and a vector $\mathbf{x}_{t}$ of $K_{x}$ exogenous variables including, in our case, only the consumption

\footnotetext{
${ }^{4}$ See [11] for a similar modeling strategy.
} 
growth rate. ${ }^{5}$ Then we assume that the vector $\mathbf{y}_{t}$ follows a VAR process. We depart from [6] by assuming that the VAR parameters are subject to regime shifts, changing according to the inferred state of the economy, as detailed below.

The model can be estimated using a two-step procedure. We first estimate the vector of posterior probability inferred by agents, and then we feed it in a time varying VAR model. This leads to a systematic coefficient variation of the VAR since the number of regimes is determined a priori and the periods where the regimes will appear with a certain probability are known. Such a feature of the model allows us to estimate the time varying VAR as a periodic VAR. To better understand the procedure, consider a VAR process of order $p$ and $q$ with time varying coefficients (see [30], chapter 17):

$$
\mathbf{y}_{t}=\nu_{t}+\sum_{i=1}^{p} \mathbf{A}_{i t} \mathbf{y}_{t-i}+\sum_{j=1}^{q} \mathbf{B}_{j t} \mathbf{x}_{t-j}+\mathbf{u}_{t}
$$

where $\mathbf{y}_{t}=\left(y_{1 t}, \ldots, y_{K y t}\right)^{\prime}$ and $\mathbf{x}_{t}=\left(x_{1 t}, \ldots, x_{K x t}\right)^{\prime}$ are the $K_{y^{-}}$-dimensional and $K_{x}$-dimensional vectors of endogenous and exogenous variables, respectively, $\nu_{t}$ is a $\left(K_{y} \times 1\right)$ time varying intercept vector, $\mathbf{A}_{i t}$ and $\mathbf{B}_{j t}$, for $i=1, \ldots, p$ and $j=1, \ldots, q$, are matrices of time varying autoregressive coefficients, and $\mathbf{u}_{t}$ is a $K_{y}$ dimensional vector of fundamental disturbances which are assumed to be normally distributed and serially uncorrelated, i.e. $\mathbf{u}_{t} \sim N\left(\mathbf{0}, \boldsymbol{\Sigma}_{t}\right)$. 6 Then, assuming that in each time $t$ the economy can either be in a boom, $b$, or in a recession, $r$, state, we can write:

$$
\begin{aligned}
\mathbf{C}_{t} & =\left[\nu_{t}, \mathbf{A}_{1 t}, \ldots, \mathbf{A}_{p t}, \mathbf{B}_{1 t}, \ldots, \mathbf{B}_{q t}\right] \\
& =\widehat{\xi}_{b, t \mid t}\left[\nu_{b}, \mathbf{A}_{1 b}, \ldots, \mathbf{A}_{p b}, \mathbf{B}_{1 b}, \ldots, \mathbf{B}_{q b}\right]+\widehat{\xi}_{r, t \mid t}\left[\nu_{r}, \mathbf{A}_{1 r}, \ldots, \mathbf{A}_{p r}, \mathbf{B}_{1 b}, \ldots, \mathbf{B}_{q b}\right] \\
& =\widehat{\xi}_{b, t \mid t} \mathbf{C}_{b}+\widehat{\xi}_{r, t \mid t} \mathbf{C}_{r}
\end{aligned}
$$

\footnotetext{
${ }^{5}$ Notice that we cannot observe the equity premium, i.e. the expected excess return, but rather only the realized excess return. However, once the dynamic relationship among the variables is estimated, the fitted series of the excess return is an estimate of the expected excess return, or equity premium.

${ }^{6}$ Notice that the consumption log-level is lagged once, i.e. current consumption has no effect on the expected equity premium. This is meant to empirically represent equation (7) where the equity premium at time $t+1$ depends on consumption surplus at time $t$. The model was also estimated including current consumption either alone and together with lagged consumption, obtaining broadly the same results.
} 
and:

$$
\Sigma_{t}=\widehat{\xi}_{b, t \mid t} \Sigma_{b}+\widehat{\xi}_{r, t \mid t} \Sigma_{r}
$$

where $\mathbf{B}_{t}$ are $\left(K_{y} \times\left(K_{y} p+K_{x} q+1\right)\right)$ coefficients matrices, $\boldsymbol{\Sigma}_{t}$ is the $\left(K_{y} \times K_{y}\right)$ covariance matrix of the residuals, and $\widehat{\xi}_{s, t \mid t}$, for $s=b, r$, are the estimated posterior probabilities of being in boom or recession. These probabilities are obtained using a Markov-Chain MonteCarlo (MCMC) procedure closely following the algorithm described in section 9.1 of [28].

Finally, the coefficients matrices $\widehat{\mathbf{B}}_{s}$ and $\widehat{\boldsymbol{\Sigma}}_{s}$, for $s=b, r$, are estimated by maximumlikelihood, using the MCMC state beliefs, $\widehat{\xi}_{s, t \mid t}$, as weights. More specifically, if we assume that the matrices $\mathbf{B}$ depend on an $(N \times 1)$ vector $\gamma$ of fixed, time invariant, parameters, while the $\boldsymbol{\Sigma}_{t}$ are assumed to depend on an $(M \times 1)$ vector $\sigma$ of fixed parameters (with $\sigma$ disjoint of and unrelated with $\gamma$ ), and, finally, assuming that $u_{t}$ is a Gaussian noise process, that is, $\mathbf{u}_{t} \sim N\left(0, \boldsymbol{\Sigma}_{t}\right)$, the log-likelihood function of the model is:

$$
\ln l(\gamma, \sigma)=-\frac{K_{y} T}{2} \ln 2 \pi-\frac{1}{2} \sum_{t=1}^{T} \ln \left|\boldsymbol{\Sigma}_{t}\right|-\frac{1}{2} \sum_{t=1}^{T} \mathbf{u}_{t}^{\prime} \boldsymbol{\Sigma}_{t} \mathbf{u}_{t}
$$

Once $\widehat{\mathbf{B}}_{s}$ and $\widehat{\boldsymbol{\Sigma}}_{s}$ are obtained, we have an estimate of the dynamic relationship among the variables. What we need to know now is how the equity premium, approximated by the fitted excess return on equity, reacts to changes in consumption across the two regimes. Within the VAR framework this can be accomplished by an impulse response analysis which allows to trace out the effect of an exogenous fundamental shock, or innovation, in consumption on the equity premium. Since consumption is treated as an exogenous variable in our model, we are not concerned with the structural correlation among fundamental shocks to endogenous variables, and we do not need to impose any theoretical structure on the VAR.

As is standard for impulse responses, these illustrate expected changes in the endogenous variables after a one standard deviation shock to one of the fundamental disturbances. In our model, we are interested in the response of the equity premium to a shock to the exogenous variable given by consumption of nondurables. However, since the VAR coefficients are 
estimated conditioning on the probability of being in one of the two regimes, what we obtain are regime-dependent impulse response functions, that is functions conditional on the regime prevailing at the time of the disturbance continuing to prevail throughout the duration of the responses. Therefore the analysis using impulse responses is valid only as long as each regime is persistent and the response horizon is not too long. In a model with $m$ regimes, $K_{y}$ endogenous variables and $K_{x}$ exogenous variables, $m K_{y} K_{x}$ regime-dependent impulse responses can be estimated, which are formally given by:

$$
E_{t}\left(y_{t+h} \mid u_{x t}=\sigma_{x}, \Omega_{t-1}\right)-E_{t}\left(y_{t+h} \mid \Omega_{t-1}\right)=\left.\frac{\partial E_{t}\left(y_{t+h}\right)}{\partial u_{x, t}}\right|_{s_{t}=\ldots=s_{t+h}=i}=\theta_{x i, h} \text { for }>=0
$$

where $E_{t}\left(y_{t+h}\right)$ is the expected level of the endogenous variable $y$ at time $t+h$ following a one standard deviation shock to the exogenous variable disturbance $u_{x}$ having place at time $t$ under the hypothesis that the regime $i$ prevailing at time $t$ will be prevailing at each horizon $h$. $\Omega_{t-1}$ is the agent's information set at time $t$. The impulse response function is given by the series of $K_{y}$-dimensional response vectors $\theta_{x i, 1}, \ldots, \theta_{x i, h}$, and is estimated following the algorithm described by [33].

\section{Data, regimes estimation and model selection}

We test the habits formation hypothesis on the U.S. postwar economy. The dataset is quarterly over the sample period 1952:1 to 2010:4. As a measure of the risk free rate of return, $R R E L_{t}$, we use the difference between the begin of quarter average of bid and ask monthly quotes for 30 day U.S. Treasury bills rate in the secondary market provided by CRSP and its 12-months backward moving average. Computing this difference is a standard way to obtain a stochastically detrended measure of the risk free rate (see [6] and [27]). The equity premium, ep, is proxied by the excess return of equities and is computed as the difference between the total market return calculated on the S\&P composite index provided by Robert Shiller at his website ${ }^{7}$ and the 30 day U.S. Treasury Bill rate. The consumption

\footnotetext{
${ }^{7}$ http://www.econ.yale.edu/ shiller/
} 
series included in the VAR, $c_{t}$, is per capita consumption of nondurables and services (NDS) computed as suggested by [36] in order to avoid problems related to the addition of chainweighted series. The consumption series used to estimate the probabilities of being in boom or recession, $\Delta c_{t}$, is the growth rate of NDS. All series are in natural logarithm and deflated using the personal consumption expenditure (PCE) chain-type index (2005=100) to obtain variables in real terms. The NDS and the PCE price index are taken from the NIPA tables of the U.S. Bureau of Economic Analysis (BEA). Table 1 shows the summary statistics of the data.

[Table 1 about here.]

In order to check for the adequacy of the empirical specification, we perform the ADFGLS ([18]) and the KPSS ([29]) unit root tests on the variables included in the VAR. The test statistics reported in Table 2 show that while the risk-free rate and the equity premium can be considered stationary, the consumption series exhibits a unit root. Nevertheless we leave consumption in level since we know that (see, e.g., [34]) in such a case the VAR estimated coefficients will have the same asymptotic distribution as if we included consumption in first difference.

[Table 2 about here.]

\subsection{Regimes estimation}

We estimate the Monte Carlo Markov Chain model for consumption growth outlined in subsection 3, using the quarterly data series of the NDS consumption growth rates. We name boom states those characterized by a high growth rate of the NDS series, while recession states correspond to periods of low NDS growth rates.

[Figure 1 about here.]

Figure 1 shows that the algorithm is able to pick up the historical business cycles of the U.S. economy. It plots the estimated posterior probability of being in the low NDS growth 
rate state, showing how the Markov-switching model is able to capture fairly well the U.S. recessions as chronicled by the official NBER business cycle dates (the gray areas in the graph) ${ }^{8}$

The transition matrix is reported in Table 3 along with the parameters estimates. The estimated probabilities of switching from the two states are $5.81 \%$ and $17.2 \%$, respectively. This implies an average duration of around 4 years for the high NDS consumption growth rate state, and slightly more than one year for the low NDS growth rate state.

[Table 3 about here.]

\subsection{Model selection}

In order to select an appropriate lag order for the endogenous variables in the VAR model, namely the risk-free rate and the equity premium, we compute standard information criteria, i.e. Akaike's Information Criterion (AIC), Hannan-Quinn Information Criterion (HQC) and Schwarz's Information Criterion (SIC), starting from a maximum lag order of 8. The value of each criterion is reported in Table 4. The AIC reaches its minimum at $p=8$, while the HQC is minimized at $p=3$ and the SIC for $p=1$. [30] (chapter 4) explains that the AIC is designed to minimize the model forecast error variance. Thus, models based on AIC may produce better forecasts although they may not estimate correctly the order of the underlying data generation process. On the contrary, HQC is a consistent VAR order selection criterion, while the SIC is strongly consistent, i.e. they select consistent and strongly consistent, respectively, estimators of the VAR process order. Since the purpose of our analysis is more focused on recovering the correct underlying data generation process to obtain a satisfactory picture of the dynamic relationship among the variables involved, we rely on the SIC and estimate a VAR model of order $1 .{ }^{9}$

[Table 4 about here.]

\footnotetext{
${ }^{8}$ see http://www.nber.org/cycles/cyclesmain.html.

${ }^{9}$ We also estimated the model with 2 and 3 lags obtaining the same qualitative results.
} 


\section{Results}

The theoretical model developed in Section 2 predicts that when the economy is facing a downturn, being the surplus consumption level low and close to habit, the equity premium will react to consumption shocks much more than in booms. We assume that the joint data generation process of the risk-free rate of return and the equity premium, conditional on the exogenous consumption log-level, is characterized by a VAR process subject to regime shifts, the latter following a Markov process that agents cannot observe but can infer from consumption growth data. We test the implication of the theoretical model by looking at the impulse response functions. The impulse response function of the excess return series following a consumption shock is a direct measure of the reaction of the equity premium (i.e. expected excess return) to consumption changes (measured by shocks to the consumption series). As detailed in section 3, being the habits stock slow moving, an increase in consumption when the economy is in a boom state will increase the surplus consumption level, while during recessions the opposite occurs: A decrease in consumption, given the slow moving habits, will decrease the surplus consumption level. Since the stock and the process of habits are unobservable, the probability of the economy being in recession or in boom is obtained using the MCMC procedure and then fed in the VAR model maximum likelihood estimation as described in section 3. Hence, we first estimate the time-varying VAR model of order 1, and then we simulate a one standard deviation (s.d.) shock to consumption under the two regimes, i.e. boom and recession.

[Figure 2 about here.]

Figure 2 shows the impulse response functions of $R R E L$ and $e p$ to a one s.d. shock to consumption in regime 1 (top row) and regime 2 (bottom row) for a simulation horizon of 20 quarters. Standard percentile intervals (see, e.g., 15) at 95\% level obtained through non-parametric bootstrap of the estimated impulse responses are also shown. Following a negative shock to the consumption level there is, as expected, an increase in the equity premium (expected excess return). We will concentrate our discussion on the response of the 
equity premium, i.e. the right-hand-side of Figure 2. The equity premium response is much larger in the second regime, corresponding to recession, than in the first one. This is consistent with our model: When the consumption surplus level is small, which is a reasonable assumption in recession, the equity premium reaction to a consumption shock is larger than under a boom state. This is because the investors are more risk averse in recessions than in booms, and their reaction to a consumption change will be sharper. In recession the equity premium increases as much as 150 basis points, with respect to the expected mean without shocks, after two quarters from the shock. It then stabilizes at a $2 \%$ level from the sixth quarter onwards. On the contrary, following a negative consumption shock in boom, the equity premium increases by around 100 basis points after one quarter and it then converges to $1 \%$ from the sixth quarter on. Although the responses have the expected signs, none are significantly different from zero all over the simulation horizon. Notice that both the risk-free rate and the equity premium responses, though being computed as not cumulated, stabilize at a value much different from zero, not showing any tendency to converge to zero, not even at larger simulation horizon. This is due to the unit root process present in the consumption log-level series. So far the empirical results have supported the predictions of our theoretical models since the equity premium response to a consumption shock appears to be larger in recessions than in booms. However, this difference in the response magnitude could be statistically equal to zero. To formally test this possibility, we compute the difference between the average response of the equity premium in recessions and in booms along with the bootstrapped confidence intervals of such difference in means.

[Figure 3 about here.]

Results are shown in Figure 3. The 95\% confidence bands include zero all over the simulation horizon. This means that the equity premium response in recession is insignificantly different from the response in boom. Investors' reaction to the same shock is insignificantly different in recession with respect to boom, under the expectation that the economy state most likely at the time of the shock will be lasting for the whole simulation horizon. These results appear to be unfavorable to the specific habit formation hypothesis used to construct 
our theoretical model, i.e. external habit formation with the surplus consumption measured as the difference between the actual consumption level and the habits stock. Various experiments to check the robustness of such results have been conducted using different lags of the endogenous and exogenous variables in the VAR, and using the consumption growth rate rather than the consumption log-level. The results remain broadly the same.

\section{Conclusion}

Habit formation has been widely used in the literature on asset pricing implications of macroeconomic models as a possible solution to several empirical anomalies in finance. We develop a model of asset pricing which has clear implications about the empirical relationship between the current level of consumption and the equity premium over the business cycle. In order to test these implications we use a novel approach to specify a multivariate econometric model where all parameters are subject to Markovian regime switching clear to interpret.

Estimation results show that following a one standard deviation shock to consumption, the equity premium response during recessions is insignificantly different than the response in booms. We interpret this result as evidence against the external habit formation hypothesis in investor's behavior.

\section{Acknowledgments}

We would like to thank Bruce Mizrach and seminar participants at Baruch College (CUNY), Stevens Institute of Technology, the $18^{\text {th }}$ SNDE Annual Symposium (Novara 2010) and the $20^{\text {th }}$ Tor Vergata Conference on Money, Banking and Finance (Rome 2011) for helpful comments. All errors are ours. 


\section{Appendix A: Proofs and Derivations}

Proof of Proposition 2.1. We take a second order Taylor expansion at the points $C_{t+1}-$ $X_{t+1}=C_{t}-X_{t}$ and $r_{t+1}=E_{t}\left(r_{t+1}\right)$ of the function

$$
G\left(C_{t+1}-X_{t+1}, r_{t+1}\right) \equiv \frac{\beta u^{\prime}\left(C_{t+1}-X_{t+1}\right)}{u^{\prime}\left(C_{t}-X_{t}\right)}\left[r_{t+1}-E_{t}\left(r_{t+1}\right)\right]
$$

the expected value of which equals the covariance entering the equity premium in equation (6). ${ }^{10}$

$$
\begin{aligned}
& \left.G\left(C_{t+1}-X_{t+1}, r_{t+1}\right)\right|_{C_{t}-X_{t}, E_{t}\left(r_{t+1}\right)}=\frac{\beta u^{\prime}\left(C_{t}-X_{t}\right)}{u^{\prime}\left(C_{t}-X_{t}\right)}\left[E_{t}\left(r_{t+1}\right)-E_{t}\left(r_{t+1}\right)\right]=0 ; \\
& \left.\frac{\partial G\left(C_{t+1}-X_{t+1}, r_{t+1}\right)}{\partial\left(C_{t+1}-X_{t+1}\right)}\right|_{C_{t}-X_{t}, E_{t}\left(r_{t+1}\right)}=\frac{\beta u^{\prime \prime}\left(C_{t}-X_{t}\right)}{u^{\prime}\left(C_{t}-X_{t}\right)}\left[E_{t}\left(r_{t+1}\right)-E_{t}\left(r_{t+1}\right)\right]=0 \\
& \left.\frac{\left.\partial G\left(C_{t+1}-X_{t+1}, r_{t+1}\right)\right]}{\partial r_{t+1}}\right|_{C_{t}-X_{t}, E_{t}\left(r_{t+1}\right)}=\frac{\beta u^{\prime}\left(C_{t}-X_{t}\right)}{u^{\prime}\left(C_{t}-X_{t}\right)}=\beta \\
& \left.\frac{\partial^{2} G\left(C_{t+1}-X_{t+1}, r_{t+1}\right)}{\partial\left(C_{t+1}-X_{t+1}\right)^{2}}\right|_{C_{t}-X_{t}, E_{t}\left(r_{t+1}\right)}=\frac{\beta u^{\prime \prime \prime}\left(C_{t}-X_{t}\right)}{u^{\prime}\left(C_{t}-X_{t}\right)}\left[E_{t}\left(r_{t+1}\right)-E_{t}\left(r_{t+1}\right)\right]=0 ; \\
& \left.\frac{\partial^{2} G\left(C_{t+1}-X_{t+1}, r_{t+1}\right)}{\partial\left(r_{t+1}\right)^{2}}\right|_{C_{t}-X_{t}, E_{t}\left(r_{t+1}\right)}=0 \\
& \left.\frac{\partial^{2} G\left(C_{t+1}-X_{t+1}, r_{t+1}\right)}{\partial\left(C_{t+1}-X_{t+1}\right) \partial r_{t+1}}\right|_{C_{t}-X_{t}, E_{t}\left(r_{t+1}\right)}=\frac{\beta u^{\prime \prime}\left(C_{t}-X_{t}\right)}{u^{\prime}\left(C_{t}-X_{t}\right)}
\end{aligned}
$$

\footnotetext{
${ }^{10}$ Recall that the second-order approximation to $G(X, Y)$ near $X=\bar{X}$ and $Y=\bar{Y}$ is:

$$
\begin{aligned}
G(X, Y) \simeq & G(\bar{X}, \bar{Y})+G_{X}(\bar{X}, \bar{Y})(X-\bar{X})+G_{Y}(\bar{X}, \bar{Y})(Y-\bar{Y}) \\
& +\frac{1}{2} G_{X X}(\bar{X}, \bar{Y})(X-\bar{X})^{2}+\frac{1}{2} G_{Y Y}(\bar{X}, \bar{Y})(Y-\bar{Y})^{2} \\
& +G_{X Y}(\bar{X}, \bar{Y})(X-\bar{X})(Y-\bar{Y}) .
\end{aligned}
$$
}


Therefore:

$$
\begin{aligned}
G\left(C_{t+1}-X_{t+1}, r_{t+1}\right) \approx & \beta\left[r_{t+1}-E_{t}\left(r_{t+1}\right)\right]+\frac{\beta u^{\prime \prime}\left(C_{t}-X_{t}\right)}{u^{\prime}\left(C_{t}-X_{t}\right)} . \\
& {\left[\left(C_{t+1}-X_{t+1}\right)-\left(C_{t}-X_{t}\right)\right]\left[r_{t+1}-E_{t}\left(r_{t+1}\right)\right] . }
\end{aligned}
$$

Taking conditional expectations of both sides of equation (15), yields:

$$
\begin{aligned}
E_{t}\left[G\left(C_{t+1}-X_{t+1}, r_{t+1}\right)\right]= & \operatorname{Cov}_{t}\left[\frac{\beta u^{\prime}\left(C_{t+1}-X_{t+1}\right)}{u^{\prime}\left(C_{t}-X_{t}\right)}, r_{t+1}\right] \\
\approx & \frac{\beta u^{\prime \prime}\left(C_{t}-X_{t}\right)}{u^{\prime}\left(C_{t}-X_{t}\right)} \cdot \\
& E_{t}\left\{\left[\left(C_{t+1}-X_{t+1}\right)-\left(C_{t}-X_{t}\right)\right] .\right. \\
& {\left.\left[r_{t+1}-E_{t}\left(r_{t+1}\right)\right]\right\} } \\
= & \beta \frac{C_{t} u^{\prime \prime}\left(C_{t}-X_{t}\right)}{u^{\prime}\left(C_{t}-X_{t}\right)} \cdot \frac{1}{C_{t}} . \\
& \operatorname{Cov}_{t}\left[\left(C_{t+1}-X_{t+1}\right), r_{t+1}\right] .
\end{aligned}
$$

Hence equation (6) becomes:

$$
E_{t}\left(r_{t+1}\right)-r_{t+1}^{f} \approx\left(1+r_{t+1}^{f}\right) \beta \frac{\gamma}{C_{t}-X_{t}} \operatorname{Cov}_{t}\left[\left(C_{t+1}-X_{t+1}\right), r_{t+1}\right]
$$

where

$$
\frac{\gamma}{\left(C_{t}-X_{t}\right) / C_{t}}=\frac{-C_{t} u^{\prime \prime}\left(C_{t}-X_{t}\right)}{u^{\prime}\left(C_{t}-X_{t}\right)}
$$

denotes the local curvature of the utility function.

Proof of Corollary 2.2. Taking the first derivative of equation (7) with respect to current consumption, yields:

$$
\frac{\partial\left[E_{t}\left(r_{t+1}\right)-r_{t+1}^{f}\right]}{\partial C_{t}} \approx-\left(1+r_{t+1}^{f}\right) \beta \frac{\gamma}{\left(C_{t}-X_{t}\right)^{2}} \operatorname{Cov}_{t}\left[\left(C_{t+1}-X_{t+1}\right), r_{t+1}\right]
$$

which measures the variation of the equity premium following a consumption change, i.e. the equity premium response to a consumption shock. From equation 16 we see that a lower 
value of the term $C_{t}-X_{t}$ (i.e. a consumption level closer to the habits stock) entails a larger response of the equity premium to changes in consumption. 


\section{References}

[1] Abel, A.B. (1990) Asset pricing under habit formation and catching up with the Joneses, American Economic Association Papers and Proceedings, 80(2): 38-42.

[2] Abel, A.B. (1999) Risk premia and term premia in general equilibrium, Journal of Monetary Economics, 43(1): 3-33.

[3] Boschi, M., d'Addona, S., and Goenka, A. (2009) Testing habits in an asset pricing model, CREI Working papers, 0509 .

[4] Boschi, M., and Goenka, A. (2012) Relative risk aversion and the transmission of financial crises, Journal of Economic Dynamics and Control, 36(1): 85-99.

[5] Braun, P.A., Constantinides, G.M., and Ferson, W.E. (1993) Time nonseparability of aggregate consumption: International evidence, European Economic Review, 37(5): 897-920.

[6] Campbell, J.Y. (1991) A variance decomposition for stock returns, Economic Journal, 101: 157-179.

[7] Campbell, J.Y., and Cochrane, J.H. (1999) By force of habit: A consumption-based explanation of gggregate stock market behavior, Journal of Political Economy, 107(2): 205-251.

[8] Campbell, J.Y., and Deaton, A.S. (1989) Why is consumption so smooth, Review of Economic Studies, 56(3): $357-373$.

[9] Carroll, C.D., Overland, J., and Weil, D.N. (2000) Saving and growth with habit formation, American Economic Review, 90: 341-355.

[10] Carroll, C.D., and Weil, D.N. (1994) Saving and growth: A Reinterpretation, Carnegie-Rochester Conference Series on Public Policy, 40: 133-192.

[11] Cecchetti, S.G., Lam, P.S. and Mark, N.C. (1993) The equity premium and the risk-free rate: Matching the moments, Journal of Monetary Economics 31(1): 21-46.

[12] Constantinides, G.M. (1990) Habit formation: A resolution of the equity premium puzzle, Journal of Political Economy, 98(2): 519-543.

[13] Dunn, K.B., and Singleton, K.J. (1986) Modeling the term structure of interest rates under nonseperable utility and durability of goods, Journal of Financial Economics, 17(1): 27-55.

[14] Dynan, K. (2000) Habit formation in consumer preferences: Evidence from panel data, American Economic Review 9(3): 391-406.

[15] Efron, B., and Tibshirani, R.J. (1993) An introduction to the bootstrap, New York: Chapman and Hall.

[16] Ehrmann, M., Ellison, M., and Valla, N. (2003) Regime-dependent impulse response functions in a Markov-switching vector autoregression model, Economics Letters, 78: 295-299.

[17] Eichenbaum, M.S., Hansen, L.P., and Singleton, K.J. (1988) A time series analysis of representative agent models of consumption and leisure under uncertainty, Quarterly Journal of Economics, 103(1): 
$51-78$.

[18] Elliott, G., Rothenberg, T.J. and Stock, J.H. (1996) Efficient tests for an autoregressive unit root, Econometrica 64(4): 813-36.

[19] Epstein, L.G., and Zin, S. (1989) Substitution, risk aversion, and the temporal behavior of consumption growth and asset returns : A theoretical framework, Econometrica, 57(4): 937-969.

[20] Epstein, L.G., and Zin, S. (1991) Substitution, risk aversion, and the temporal behavior of consumption growth and asset returns: An empirical analysis, Journal of Political Economy, 99(2): 263-286.

[21] Ferson, W.E., and Constantinides, G.M. (1991) Habit persistence and durability in aggregate consumption: Empirical tests, Journal of Financial Economics, 29(2): 199-240.

[22] Fuhrer, J.C. (2000) Habit formation in consumption and its implications for monetary policy models, American Economic Review, 90: 367-390.

[23] Gruber, J.W. (2004) A present value test of habits and the current account, Journal of Monetary Economics, 51: 1495-1507.

[24] Hamilton, J.D. (1989) A new approach to the economic analysis of nonstationary time series and the business cycle, Econometrica, 57(2): 357-384.

[25] Hamilton, J.D. (1990) Analysis of time series subject to changes in regime, Journal of Econometrics, 45(1-2): 39-70.

[26] Heaton, J. (1993) The interaction between time-nonseparable preferences and time aggregation, Econometrica, 61(2): 353-385.

[27] Hodrick, R.J. (1992) Dividend yields and expected stock returns: Alternative procedures for inference and measurement, Review of Financial Studies, 5(3): 357-386.

[28] Kim, C.J., and Nelson, C.R. (1999) State-space models with regime switching, Cambridge: MIT Press.

[29] Kwiatkowski, D., Phillips, P.C.B., Schmidt, P., and Shin, Y. (1992) Testing the null hypothesis of stationarity against the alternative of a unit root: How sure are we that economic time series have a unit root? Journal of Econometrics, 54(1-3) 159-178.

[30] Lütkepohl, H. (2007) New introduction to multiple time series analysis, Berlin: Springer.

[31] Mankiw, N.G. and Zeldes, S.P. (1991) The consumption of stockholders and nonstockholders, Journal of Financial Economics, 29(1): 97-112.

[32] Muellbauer, J. (1988) Habits, rationality and myopia in the life cycle consumption function, Annales d'Economie et de Statistique, 9:47-70.

[33] Pesaran, M.H., Schuermann, T., and Weiner, S.M. (2004) Modelling regional interdependencies using a global error-correcting macroeconometric model, Journal of Business Economics and Statistics, 22: 126-162.

[34] Sims, C.A., Stock, J.H., Watson, M.W. (1990) Inference in linear time series models with some unit 
roots, Econometrica, 58(1): 113-144.

[35] Smets, F., and Wouters, R. (2003) An estimated dynamic stochastic general equilibrium model of the Euro area, Journal of the European Economic Association, 1(5): 1123-1175.

[36] Whelan, K. (2002) A guide to U.S. chain aggregated NIPA data, Review of Income and Wealth, 48(2): 217-33.

[37] Weil, P. (1990) Nonexpected utility in macroeconomics, Quarterly Journal of Economics, 105(29-42). 
Figure 1: Posterior probabilities of the consumption low growth rate

This figure shows the estimated posterior probabilities of being in a consumption low growth rate state coupled with the official NBER recession dates (shadow area). Data employed in the estimation are quarterly from I-1952 to IV-2010.

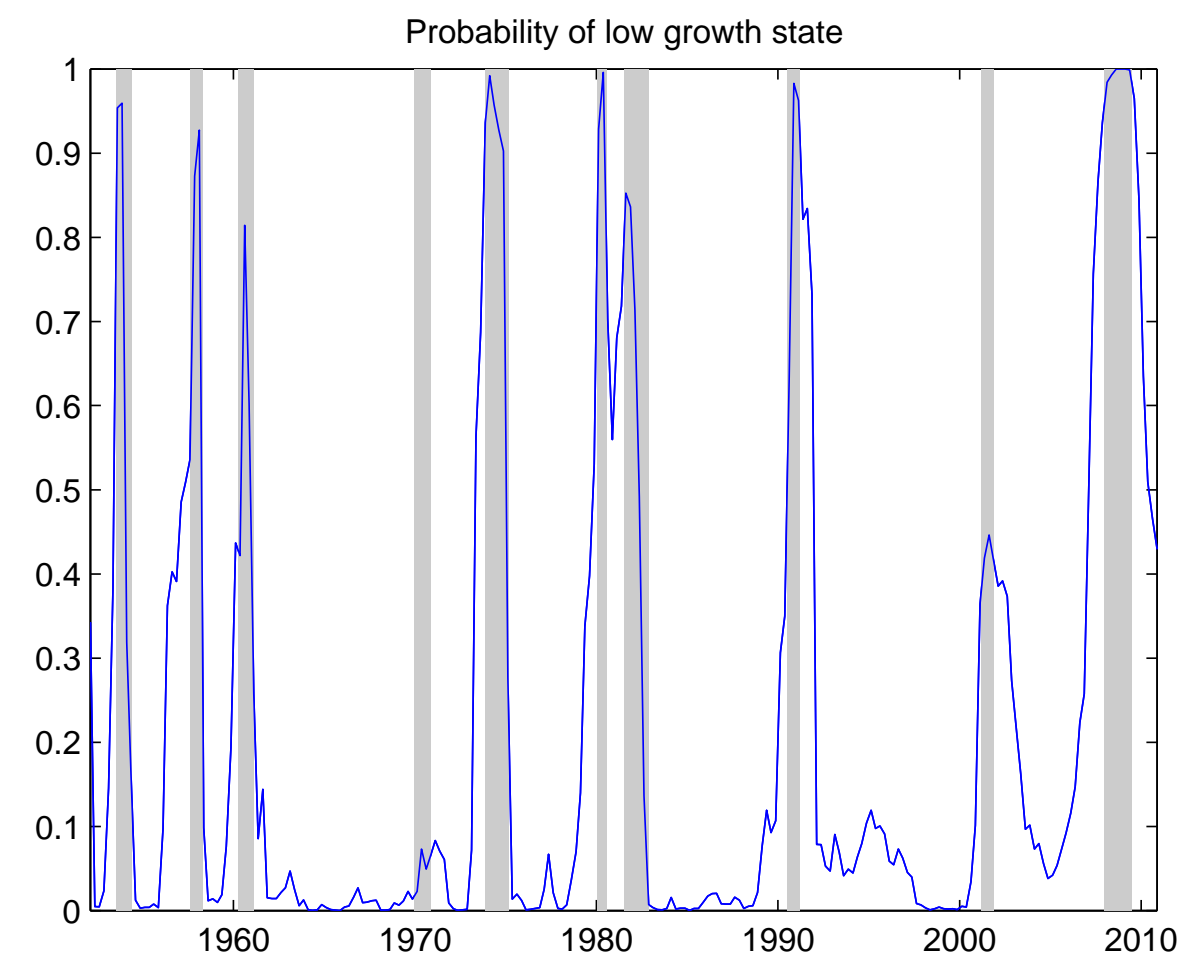


Figure 2: Impulse response functions

This figure shows the responses of $R R E L$ (l.h.s. column) and $e p$ (r.h.s. column) in regime 1 (top row) and regime 2 (bottom row) to a one s.d. shock to $c$.
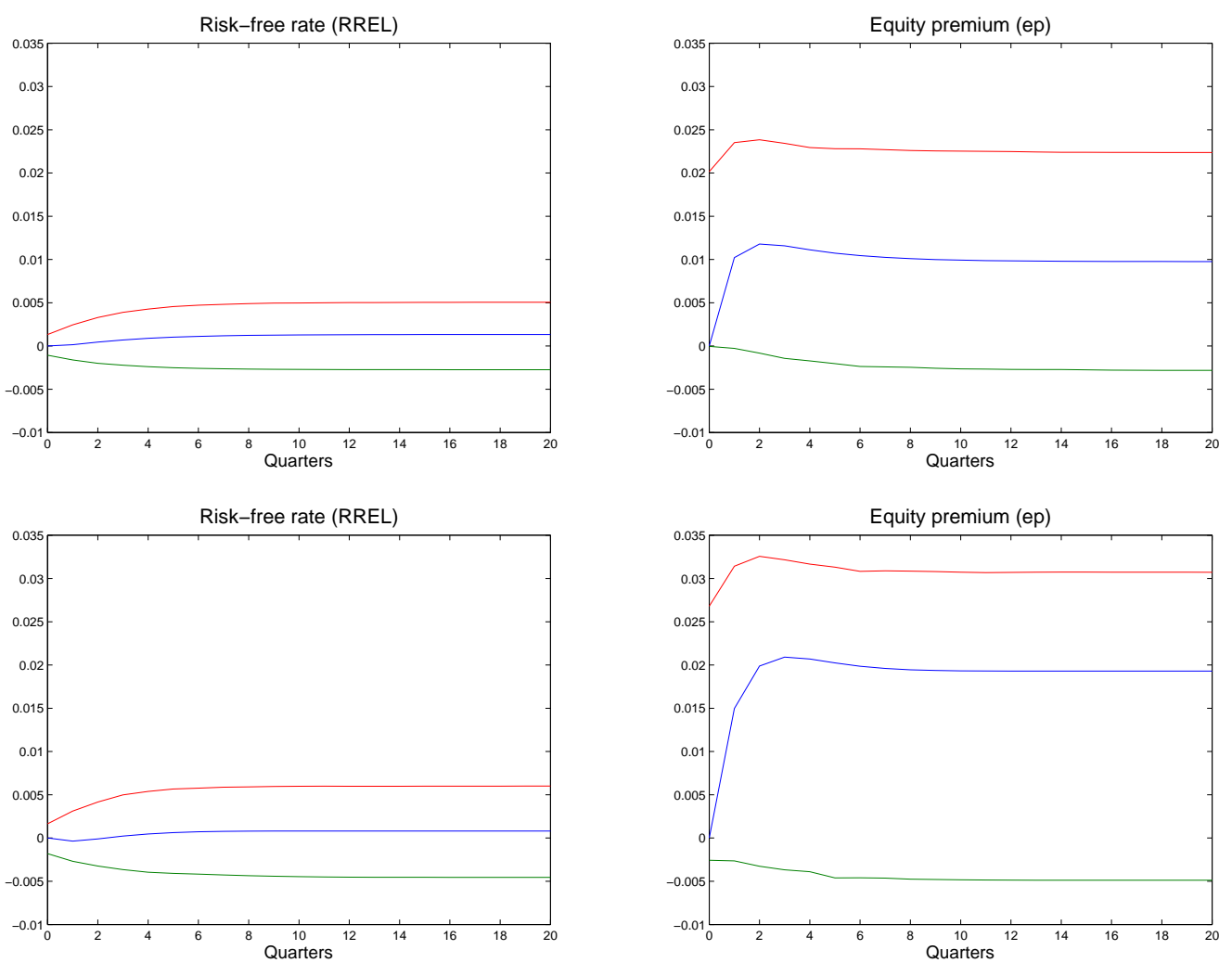
Figure 3: Mean difference in the response functions

This figure shows the difference in the average response of the equity premium in booms and recessions along with the bootstrapped confidence intervals.

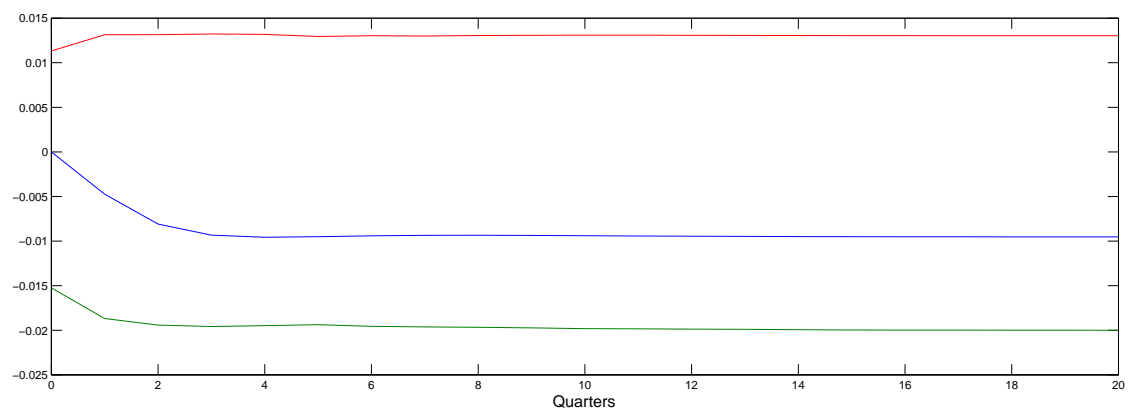


Table 1: Summary statistics

This table reports the summary statistics computed for the variables included in the VAR model over the whole sample size. Data are quarterly from I-1952 to IV-2010.

\begin{tabular}{lccc}
\hline & $R R E L$ & $e p$ & $c$ \\
\hline$R R E L$ & \multicolumn{3}{c}{ Panel A: Correlation matrix } \\
$e p$ & 1.0000 & -0.1226 & -0.1054 \\
$c$ & & 1.0000 & -0.1697 \\
& \multicolumn{3}{c}{ Panel B: Univariate Summary Statistics } \\
\hline \multicolumn{3}{l}{ Mean } & \multicolumn{3}{c}{0.00435} & 9.68290 \\
Standard deviation & -0.00013 & 0.07451 & 0.34753 \\
Autocorrelation & 0.01152 & 0.28630 & 0.98890 \\
\hline
\end{tabular}


Table 2: Unit root tests statistics

This table reports unit root test statistics for the variables included in the model and their first difference.

\begin{tabular}{lcc}
\hline Variable & \multicolumn{2}{c}{ Tests statistics } \\
\hline RREL & ADF-GLS $(p$-value) & KPSS (5\% c.v.) \\
$\Delta R R E L$ & $-5.81(1.25 \mathrm{e}-008)$ & $0.1615(0.463)$ \\
$e p$ & $-4.65(3.88 \mathrm{e}-006)$ & $0.0099(0.463)$ \\
$\Delta e p$ & $-2.16(0.0295)$ & $0.4587(0.463)$ \\
$c$ & $-0.94(0.3109)$ & $0.0239(0.463)$ \\
$\Delta c$ & $0.72(0.8706)$ & $4.7902(0.463)$ \\
\hline
\end{tabular}


Table 3: Estimation of regime-switching consumption growth process parameters

This table reports the estimated parameters of the regime-switching process for the U.S. postwar consumption growth. Data employed in the estimation are quarterly from I-1952 to IV-2010.

\begin{tabular}{lccc}
\hline State & Mean growth rate & Switching probability & Average Duration (qts.) \\
& & & \\
\hline Regime 1 & $0.062 \%$ & 0.0547 & 18.3 \\
Regime 2 & $-0.010 \%$ & 0.1721 & 5.8 \\
\hline
\end{tabular}


Table 4: Lag Selection

This table reports the values of the information criteria computed at different lags of the VAR endogenous variables.

\begin{tabular}{lccc}
\hline Lag order & \multicolumn{3}{c}{ Selection criteria } \\
\hline 1 & AIC & HQC & SIC \\
\hline 2 & -15.146 & -15.122 & $\mathbf{- 1 5 . 0 8 7}$ \\
3 & -15.188 & -15.140 & -15.070 \\
4 & -15.195 & $-\mathbf{1 5 . 1 2 3}$ & -15.017 \\
5 & -15.210 & -15.114 & -14.972 \\
6 & -15.222 & -15.102 & -14.924 \\
7 & -15.224 & -15.079 & -14.865 \\
8 & -15.206 & -15.036 & -14.786 \\
\hline
\end{tabular}

